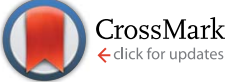

Cite this: Chem. Sci., 2017, 8, 1337

\title{
A metal-mediated base pair that discriminates between the canonical pyrimidine nucleobases $\uparrow$
}

\author{
Biswarup Jash, ${ }^{\text {ab }}$ Philipp Scharf, ${ }^{a}$ Nikolas Sandmann, ${ }^{a}$ Célia Fonseca Guerra, ${ }^{\text {*c }}$ \\ Dominik A. Megger ${ }^{\star d}$ and Jens Müller ${ }^{\star a b}$
}

A nucleoside analogue comprising the ligand $1 \mathrm{H}$-imidazo[4,5-f][1,10]phenanthroline $(\mathrm{P})$ was applied to develop a molecular beacon capable of discriminating the canonical nucleobases cytosine and thymine. The beacon is based on the formation of a stable $\mathrm{Ag}^{+}$-mediated base pair between $\mathrm{P}$ and cytosine, whereas the presence of $\mathrm{Ag}^{+}$strongly destabilizes nucleic acids comprising an artificial base pair between $\mathrm{P}$ and thymine. Metal-mediated base pair formation was investigated by temperaturedependent UV spectroscopy and CD spectroscopy and complemented by extensive DFT calculations. The molecular beacon significantly extends the application spectrum of nucleic acids with metalmediated base pairs. It is of potential use in the detection of single-nucleotide polymorphisms.

Received 4th August 2016

Accepted 12th October 2016

DOI: $10.1039 /$ c6sc03482a

www.rsc.org/chemicalscience

natural duplex conformation, ${ }^{4}$ even though a transition to

\section{Introduction}

Nucleic acids represent an optimal scaffold for the introduction of functional molecules. ${ }^{1}$ The combination of their self-assembling capability with functional moieties renders them ideal building blocks in supramolecular chemistry and nanotechnology. ${ }^{2}$ Metal-mediated base pairs represent a convenient means for the introduction of metal-based functionality into nucleic acids. In these artificial base pairs, metal ions are located in-between complementary nucleobases, formally replacing the hydrogen bonds found in canonical base pairs. ${ }^{3}$ Various experimental structures have confirmed that nucleic acid duplexes with metal-mediated base pairs still retain their

${ }^{a}$ Institut für Anorganische und Analytische Chemie, Westfälische Wilhelms-Universität Münster, Corrensstraße 30, 48149 Münster, Germany. E-mail: mueller.j@ uni-muenster.de

${ }^{b} N R W$ Graduate School of Chemistry, Westfälische Wilhelms-Universität Münster, Corrensstraße 30, 48149 Münster, Germany

${ }^{c}$ Department of Theoretical Chemistry, Amsterdam Center for Multiscale Modeling (ACMM), VU Amsterdam, De Boelelaan 1083, 1081 HV Amsterdam, The Netherlands. E-mail: c.fonsecaguerra@vu.nl

${ }^{d}$ Medizinisches Proteom-Center, Ruhr-Universität Bochum, Universitätsstraße 150, 44801 Bochum, Germany.E-mail: dominik.megger@rub.de

$\dagger$ Electronic supplementary information (ESI) available: Determination of the $\mathrm{p} K_{\mathrm{a}}$ values of $\mathbf{1}$; determination of the $\mathrm{p} K_{\mathrm{a}}$ values of $\mathbf{P}$; melting curves of duplexes with a central P:X base pair; melting curves of duplexes with a central A:T, G:C or C:T base pair; geometry-optimized structures of possible hydrogen-bonded base pairs; normalized proton-binding energies of $\mathbf{P}$ and $\mathbf{C}$; melting temperatures of the duplexes comprising a central A:T, G:C or C:T base pair; base pairing energies of hydrogen-bond mediated base pairs; equations used to fit the pD-dependent chemical shift data; full computational details; Cartesian coordinates and energies of geometry-optimized structures; MALDI spectra of oligonucleotides, synthesis and characterization of $\mathbf{1}$; characterization of P. CCDC 1489603. For ESI and crystallographic data in CIF or other electronic format see DOI: $10.1039 / \mathrm{c} 6 \mathrm{sc} 03482 \mathrm{a}$ another conformation has been established, too. ${ }^{5}$ Nucleosides used in metal-mediated base pairs can be either entirely natural, ${ }^{6}$ entirely artificial, ${ }^{7}$ or be formally derived from a natural nucleoside. ${ }^{8}$ Several applications have been proposed and developed for nucleic acids with metal-mediated base pairs. ${ }^{9}$ While most of these applications are related to the sensing of metal ions (particularly $\mathrm{Hg}^{2+}$ and $\left.\mathrm{Ag}^{+}\right),{ }^{10}$ investigations toward increasing the charge transfer properties of $\mathrm{DNA}^{11}$ or generating DNA-templated silver nanoparticles ${ }^{12}$ have also been pursued.

Moreover, the fact that metal-mediated base pairs can be processed by polymerases ${ }^{13}$ makes them interesting candidates for the use in molecular computing devices. ${ }^{14}$ Recently, nucleic acids with metal-mediated base pairs have been proposed to be useful in the recognition of nucleic acid sequences. ${ }^{15}$ We report here the first implementation of this application. Toward this end, the ligand $1 H$-imidazo[4,5-f][1,10]phenanthroline was used as artificial nucleobase. We could previously show that a nucleoside analogue $\mathbf{P}$ (Chart 1) bearing this nucleobase is capable of forming $\mathrm{Ag}^{+}$-mediated homo base pairs ${ }^{16}$ as well as hetero base pairs ${ }^{\mathbf{1 7}}$ with an artificial imidazole nucleoside. In<smiles>OC[C@H](O)Cn1cnc2c3cccnc3c3ncccc3c21</smiles>

Chart 1 Artificial nucleoside analogue $\mathrm{P}$ based on the ligand $\mathrm{H} \mathrm{H}$-imidazo[4,5-f][1,10]phenanthroline. 
this study, we establish its use in the discrimination of the canonical nucleobases cytosine and thymine by developing a turn-on fluorescence sensor.

\section{Results and discussion}

\section{Acidity constants of imidazophenanthroline}

To evaluate a possible competition between protonation and metalation of the nucleoside analogue $\mathbf{P}$, its acidity constants were determined by pD-dependent ${ }^{1} \mathrm{H}$ NMR spectroscopy. For comparison, the $\mathrm{p} K_{\mathrm{a}}$ values of the closely related 1-methyl-1Himidazo[4,5-f][1,10]phenanthroline 1 were determined, too. As can be seen from Fig. 1, S1 and $\mathrm{S} 2, \dagger$ the experimental data are fitted best under the assumption of three $\mathrm{p} K_{\mathrm{a}}$ values. Table 1 lists the acidity constants derived from these data.

The GNA nucleoside $\mathbf{P}$ is slightly more acidic than its methyl analogue 1. However, it can be anticipated that the latter data better describe the situation inside a DNA duplex, because the negative charge introduced by the phosphate group typically leads to a decrease in acidity compared to the nucleoside data. ${ }^{\mathbf{1 8}}$ The NMR data do not allow an assignment of which site is protonated at which $\mathrm{p} K_{\mathrm{a}}$ value. We therefore calculated protonbinding energies of the three nitrogen atoms in $1 \mathrm{H}$-imidazo[4,5$f][1,10]$ phenanthroline. These data (Table S1†) indicate that one of the endocyclic nitrogen atoms of the phenanthroline ring is protonated first, as both of them have essentially identical proton-binding energies, exceeding that of the imidazole nitrogen atom by more than $5 \mathrm{kcal} \mathrm{mol}^{-1}$ under aqueous conditions. Hence, the following order of protonation can be assumed: $\mathrm{N} 1$ or $\mathrm{N} 10, \mathrm{~N}_{\mathrm{im}}, \mathrm{N} 10$ or $\mathrm{N} 1$. A comparison of the $\mathrm{p} K_{\mathrm{a}}$ value of $6.0 \pm 0.1$ with the respective value in unsubstituted 1,10-phenanthroline, which amounts to $4.98,{ }^{19}$ shows that the

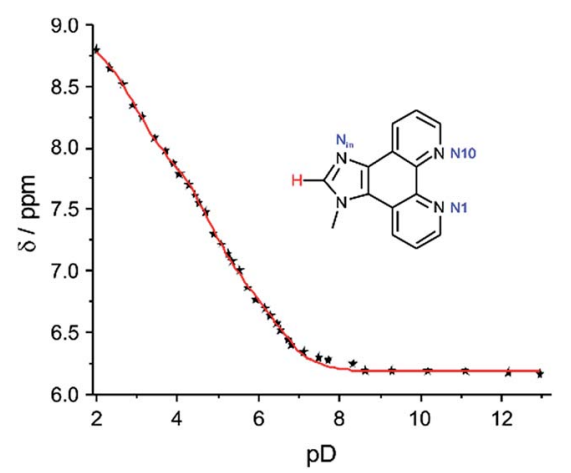

Fig. 1 Chemical shift of the imidazole hydrogen atom of 1 depending on the $\mathrm{pD}$ value, including least-squares fit assuming the presence of three distinct $\mathrm{p} K_{\mathrm{a}}$ values.

Table 1 Acidity constants of the nucleoside analogue $\mathrm{P}$ and its methyl derivative 1

\begin{tabular}{llll}
\hline Compound & $\mathrm{p} K_{\mathrm{a} 1}$ & $\mathrm{p} K_{\mathrm{a} 2}$ & $\mathrm{p} K_{\mathrm{a} 3}$ \\
\hline $\mathbf{P}$ & $5.4 \pm 0.2$ & $3.6 \pm 0.2$ & $1.3 \pm 0.2$ \\
$\mathbf{1}$ & $6.0 \pm 0.1$ & $4.3 \pm 0.1$ & $2.6 \pm 0.1$
\end{tabular}

\section{$5^{\prime}-d$ (GAG GGA PAG AAA G) $-3^{\prime}$ \\ $3^{\prime}-\mathrm{d}\left(\mathrm{CTC}\right.$ CCT XTC TTT C) $-5^{\prime}$}

Chart 2 Oligonucleotide sequence used to determine the base pairing properties of the artificial nucleoside analogue $\mathrm{P}$ opposite to a canonical pyrimidine nucleoside $\mathbf{X}$.

appended imidazole moiety leads to an increase in basicity. Concomitantly, its own basicity decreases from 7.05 for unsubstituted imidazole ${ }^{20}$ to $4.3 \pm 0.1$. The $\mathrm{p} K_{\mathrm{a}}$ values indicate that protonation of the ligand cannot be neglected when working under acidic conditions. The acidity constant $\mathrm{p} K_{\mathrm{a} 2}$ is similar to that of cytosine (1-methylcytosine, $\mathrm{p} K_{\mathrm{a}}=4.6$; deoxycytidine, $\mathrm{p} K_{\mathrm{a}}=4.17 ; 5^{\prime}$-dCMP, $\left.\mathrm{p} K_{\mathrm{a}}=4.54\right){ }^{18}$ indicating that when present in the same oligonucleotide, cytosine and the imidazole moiety of $\mathbf{P}$ may become protonated concurrently.

\section{Base pairing of $P$ with cytosine and thymine}

To investigate the applicability of the nucleoside analogue $\mathbf{P}$ in a metal-mediated base pair with a canonical pyrimidine nucleoside, oligonucleotide duplexes of the type depicted in Chart 2 were synthesized. The sequence was chosen because it had previously been used for the characterization of metalmediated base pairs formed from P:imidazole hetero mispairs, allowing an optimal comparison. ${ }^{17}$ In the present study, cytosine (C) or thymine (T) were used as the complementary nucleoside denoted $\mathbf{X}$ in Chart 2 . Information on the stability of the unnatural base pairs was derived from the melting temperatures $T_{\mathrm{m}}$ of the corresponding duplexes, determined by using temperature-dependent UV spectroscopy. All experiments were performed under slightly acidic ( $\mathrm{pH} 5.5)$, near-neutral $(\mathrm{pH}$ 6.8) and slightly alkaline $(\mathrm{pH}$ 9.0) conditions, thereby probing also the influence of nucleobase protonation and deprotonation. Silver(I) was chosen as metal ion for metalmediated base pairs, because previous studies involving $\mathbf{P}$ had shown that $\mathrm{Ag}^{+}$leads to the most significant thermal stabilization. Fig. 2 shows the melting curves of the DNA duplexes in the presence of increasing amounts of $\mathrm{AgNO}_{3}$. Table 2 lists the melting temperatures derived from these curves. They will be discussed in the following two paragraphs.

\section{Hydrogen-bond-mediated base pairs}

In the absence of $\mathrm{Ag}^{+}$, the melting temperatures are (within error limits) identical for the duplexes comprising a P:C or a P:T base pair at each of the $\mathrm{pH}$ values under investigation. The general trend is that the duplexes are more stable at lower $\mathrm{pH}$. This trend differs from that of the corresponding duplexes with a central A:T or G:C base pair (A, adenine; G, guanine), which are most stable at near-neutral pH (Fig. S4 and Table S2 $\dagger$ ). Hence, protonation/deprotonation seems to have an important effect on the stability of the metal-free P:C and P:T base pairs. Possible hydrogen-bonded P:C and P:T base pairs are shown in Chart 3. All base pairs contain either two hydrogen bonds $\left(T_{\mathrm{m}}=\right.$ $32-35{ }^{\circ} \mathrm{C}$, Chart $\left.3 \mathrm{a}-\mathrm{d}\right)$ or one bifurcated hydrogen bond $\left(T_{\mathrm{m}}=\right.$ $28{ }^{\circ} \mathrm{C}$, Chart $3 \mathrm{e}$ and $\mathrm{f}$ ). The structures of the base pairs were confirmed by DFT calculations to represent energy minima 

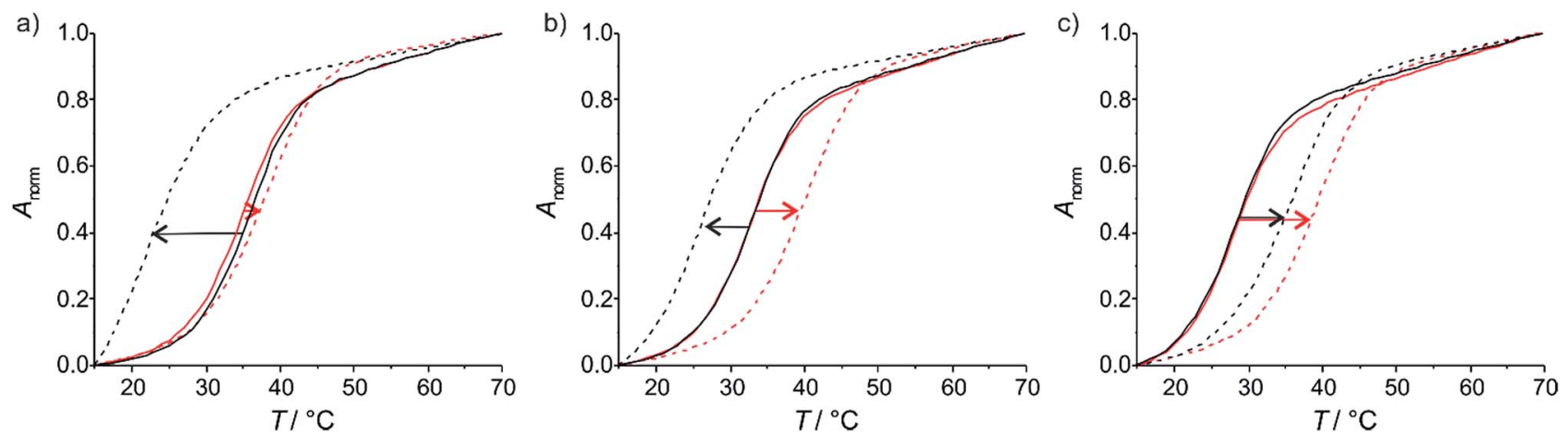

Fig. 2 Melting curves of the duplexes in the absence (solid lines) and presence (dotted lines) of one equivalent of $\mathrm{AgNO}_{3}$. The red melting curves belong to the duplex comprising a cytosine residue opposite to $\mathrm{P}$, the black ones to that with a thymine residue. (a) $\mathrm{pH} 5.5$, (b) $\mathrm{pH} 6.8$, (c) $\mathrm{pH} 9.0$.

Table 2 Melting temperatures $\left(T_{\mathrm{m}} /{ }^{\circ} \mathrm{C}\right)$ of the duplexes bearing one $\mathrm{P}: \mathrm{C}$ or $\mathrm{P}: \mathrm{T}$ base pair in the absence $\left(T_{\mathrm{m}, 0}\right)$ and presence $\left(T_{\mathrm{m}, 1}\right)$ of one equiv. of $\mathrm{AgNO}_{3}$ and change in $T_{\mathrm{m}}\left(\Delta T_{\mathrm{m}} /{ }^{\circ} \mathrm{C}\right)$ upon the addition of one equiv. of $\mathrm{AgNO}_{3}$. References are made to Chart 3 and Fig. 3, which display the proposed base pairing patterns

\begin{tabular}{|c|c|c|c|c|c|c|c|c|c|c|}
\hline $\mathrm{pH}$ & \multicolumn{5}{|c|}{$\mathbf{P}$ and $\mathbf{C}$} & \multicolumn{5}{|c|}{$\mathbf{P}$ and $\mathbf{T}$} \\
\hline 6.8 & 33 & Chart $3 a$ and $b$ & 40 & Fig. 3a & +7 & 32 & Chart $3 c$ and $d$ & 27 & - & -5 \\
\hline 9.0 & 28 & Chart 3e & 39 & Fig. 3a & +11 & 28 & Chart 3f & 37 & Fig. $3 \mathrm{~b}$ & +9 \\
\hline
\end{tabular}

(Fig. S5 $\dagger$ ). The calculations show a good correlation between computed base pairing energies and experimental melting temperature (Table $\mathrm{S} 3 \dagger$ ). In an aqueous environment, the base pairing energies of the pairs comprising two hydrogen bonds

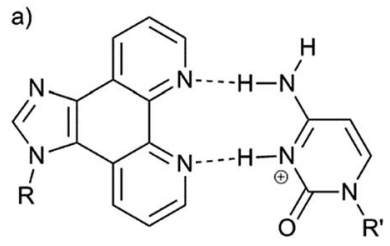<smiles></smiles>

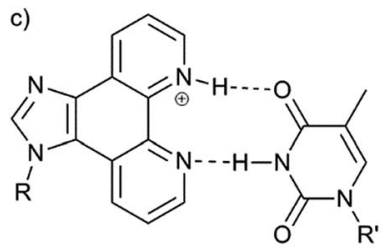

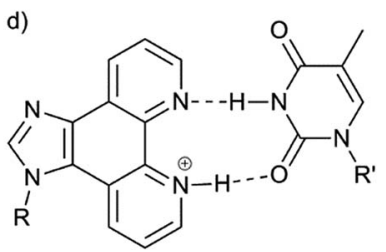<smiles></smiles><smiles></smiles>

Chart 3 Possible hydrogen-bonded base pairs. (a) $P: C(H)^{+}$; $\mathrm{P}(\mathrm{H}(\mathrm{N} 1))^{+}: \mathrm{C}$; (c) $\mathrm{P}(\mathrm{H}(\mathrm{N} 10))^{+}: \mathrm{T}$; (d) $\mathrm{P}(\mathrm{H}(\mathrm{N} 1))^{+}: \mathrm{T}$; (e) P:C; (f) P:T. are around $-10 \mathrm{kcal} \mathrm{mol}^{-1}$, coinciding with a $T_{\mathrm{m}}$ in the order of $32-35{ }^{\circ} \mathrm{C}$. The lower melting temperature of $28^{\circ} \mathrm{C}$ at $\mathrm{pH} 9$ agrees well with reduced base pairing energies of around -6 kcal $\mathrm{mol}^{-1}$, which can again be explained by the presence of one (bifurcated) hydrogen bond only.

\section{Metal-mediated base pairs}

Upon the addition of $\mathrm{AgNO}_{3}$ to the oligonucleotide duplexes, changes in the melting temperatures can be observed (Fig. 2). In all cases, the addition of the first equivalent of $\mathrm{Ag}^{+}$influences $T_{\mathrm{m}}$ the most. Excess $\mathrm{Ag}^{+}$has only minor additional effects on $T_{\mathrm{m}}$. This behaviour is typical for the formation of a mononuclear metal-mediated base pair. ${ }^{3 a}$ Interestingly, the addition of $\mathrm{AgNO}_{3}$ has dramatically different effects depending on whether cytosine or thymine is located opposite to the artificial nucleobase $\mathbf{P}$. In the case of cytosine, the final melting temperature amounts to $40{ }^{\circ} \mathrm{C}$ and is (within standard deviation) independent of the $\mathrm{pH}$. This suggests that the same $\mathbf{P}-\mathrm{Ag}^{+}-\mathbf{C}$ base pair (Fig. 3a) is formed under all conditions. In contrast, with thymine a stabilizing base pair is formed under alkaline conditions only, with a $T_{\mathrm{m}}$ of $37^{\circ} \mathrm{C}$. The similar melting temperatures of the duplex comprising this base pair and the duplexes with a $\mathbf{P}-\mathrm{Ag}^{+}-\mathbf{C}$ base pair suggest that these silver(I)-mediated base pairs are of similar composition. Most likely, the elevated $\mathrm{pH}$ facilitates the deprotonation of the thymine residue (1-methylthymine, $\mathrm{p} K_{\mathrm{a}}=10.4$; thymidine, $\mathrm{p} K_{\mathrm{a}}=$ 9.93; $5^{\prime}$-dTMP, $\left.K_{\mathrm{a}}=10.47\right),{ }^{18}$ enabling the formation of a $\mathbf{P}-\mathrm{Ag}^{+}-$ $\mathbf{T}_{-\mathrm{H}}$ base pair (Fig. 3b).

At pH 6.8 and 5.5, the presence of $\mathrm{AgNO}_{3}$ effects a significant destabilization of the duplex. The observation that one $\mathrm{Ag}^{+}$is 

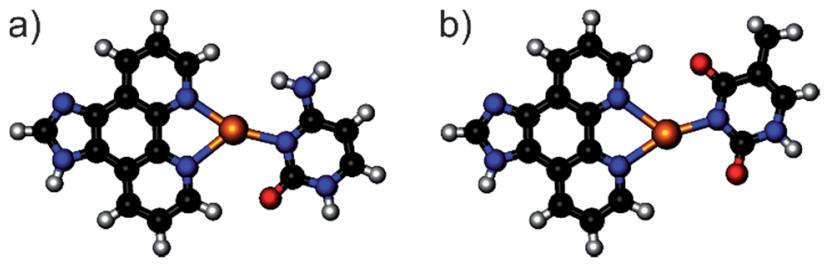

Fig. 3 Geometry-optimized structures of the silver(I)-mediated base pairs (a) $\mathrm{P}-\mathrm{Ag}^{+}-\mathrm{C}$ and (b) $\mathrm{P}-\mathrm{Ag}^{+}-\mathrm{T}_{-\mathrm{H}}$.

Table 3 Base pairing energies $\Delta E_{\mathrm{BP}}$ of hydrogen-bond mediated base pairs (kcal mol $\left.{ }^{-1}\right)^{a}$

\begin{tabular}{llcc}
\hline Entry & Base pair & Gas phase & In water \\
\hline 1 & $\mathbf{P}(\mathrm{H}(\mathrm{Im}))^{+}-\mathrm{Ag}^{+}-\mathbf{C}$ & -60.6 & -23.4 \\
2 & $\mathbf{P}-\mathrm{Ag}^{+}-\mathbf{C}$ & -47.0 & -23.1 \\
3 & $\mathbf{P}-\mathrm{Ag}^{+}-\mathbf{T}_{-\mathrm{H}}$ & -125.8 & -25.8
\end{tabular}

${ }^{a}$ The following reactions have been used to calculate the base pairing energies. (1) $[\mathbf{P}(\mathrm{H}(\mathrm{Im}))-\mathrm{Ag}]^{2+}+\mathbf{C} \rightarrow \mathbf{P}(\mathrm{H}(\mathrm{Im}))^{+}-\mathrm{Ag}^{+}-\mathbf{C} ;(2)[\mathbf{P}-\mathrm{Ag}]^{+}+\mathbf{C}$ $\rightarrow \mathbf{P}-\mathrm{Ag}^{+}-\mathbf{C} ;(3)[\mathbf{P}-\mathrm{Ag}]^{+}+\mathbf{T}_{-\mathrm{H}} \rightarrow \mathrm{P}-\mathrm{Ag}^{+}-\mathbf{T}_{-\mathrm{H}}$.

bound per duplex under all experimental conditions strongly suggests that the bidentate nucleoside $\mathbf{P}$ is metalated irrespective of $\mathrm{pH}$. The significant destabilization at $\mathrm{pH} 6.8$ and 5.5 results from the fact that the previously existing $\mathbf{P}(\mathrm{H}(\mathrm{N} 1))^{+}: \mathbf{T}$ and $\mathbf{P}(\mathrm{H}(\mathrm{N} 10))^{+}: \mathbf{T}$ base pairs can no longer be formed as a result of the metalation of $\mathbf{P}$. A reasonable assumption is that one of the bases extrudes from the duplex, therefore leading to a decrease in thermal stability.

DFT calculations support the structures of the proposed metal-mediated base pairs. Table 3 lists base pairing energies computed under the assumption that the bidentate $\mathbf{P}$ binds $\mathrm{Ag}^{+}$ first, leading to $[\mathbf{P}-\mathrm{Ag}]^{+}$(or $[\mathbf{P}(\mathrm{H}(\mathrm{Im}))-\mathrm{Ag}]^{2+}$ if protonated). The subsequent formation of the $\mathrm{Ag}^{+}-\mathbf{C}$ or $\mathrm{Ag}^{+}-\mathbf{T}_{-\mathrm{H}}$ bond is presumed to represent the stability-determining step. As can be seen from Table 3, the silver-mediated base pairs $\mathbf{P}-\mathrm{Ag}^{+}-\mathbf{C}$ and $\mathbf{P}-\mathrm{Ag}^{+}-\mathbf{T}_{-\mathrm{H}}$ are of very similar stability under aqueous conditions, corroborating the very similar melting temperatures of $37-40{ }^{\circ} \mathbf{C}$. Even a potential protonation of $\mathbf{P}$ in $\mathbf{P}-\mathrm{Ag}^{+}-\mathbf{C}$ under acidic conditions would not influence the base pairing energies. No chemically reasonable structures could be computed for a silver(I)-mediated base pair involving $\mathbf{P}$ and non-deprotonated T. This finding is in agreement with the proposal that one of the bases extrudes from the duplex when adding $\mathrm{AgNO}_{3}$ to the duplex comprising a central P:T base pair at pH 6.8 or 5.5.

Circular dichroism (CD) spectroscopy was used to investigate the structural similarity of the various duplexes. As can be seen in Fig. 4, the spectra of the duplex comprising a $\mathbf{P}-\mathrm{Ag}^{+}-\mathbf{C}$ base pair are almost identical at all three $\mathrm{pH}$ values. This agrees well with identical melting temperatures and base pair formation energies. In contrast, the spectra of the duplex with a central P:T pair differ significantly from one another, which is in agreement with their differing melting temperatures. Interestingly, the $\mathrm{CD}$ spectrum of the duplex with a $\mathbf{P}-\mathrm{Ag}^{+}-\mathbf{T}_{-\mathrm{H}}$ base pair (black dotted line) is different from the corresponding spectra of the duplex

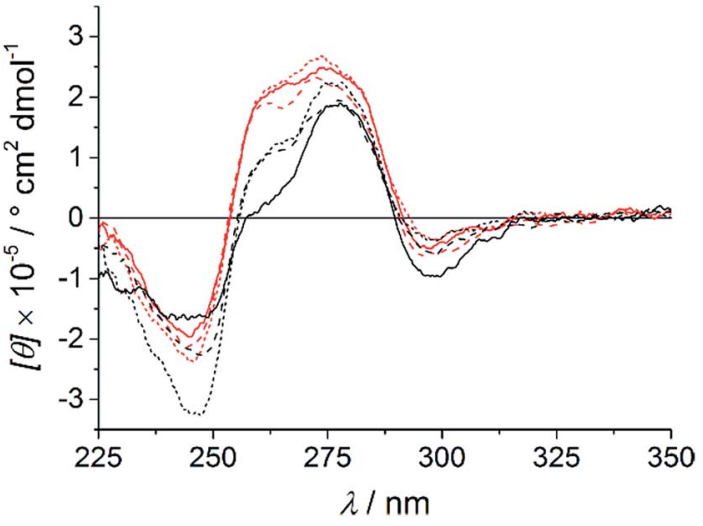

Fig. $4 C D$ spectra of the oligonucleotide duplexes with a central cytosine (red) or thymine (black) residue opposite to $\mathrm{P}$ in the presence of one equivalent of $\mathrm{AgNO}_{3}$ per duplex. $\mathrm{pH}$ 5.5: solid line; $\mathrm{pH}$ 6.8: dashed line; $\mathrm{pH}$ 9.0: dotted line.

with a $\mathbf{P}-\mathrm{Ag}^{+}-\mathbf{C}$ base pair (red spectra). Hence, despite similar melting temperatures and base pair formation energies, a distinct structural difference must exist. A closer look at the computed structures (Fig. 3) indicates that the thymine residue experiences a certain displacement within the base pair plane, which probably leads to a distortion of the overall duplex structure. In fact, the distance between the two nitrogen atoms involved in the glycosidic bonds amounts to $10.7 \AA\left(\mathbf{P}-\mathrm{Ag}^{+}-\mathbf{C}\right)$ and $11.3 \AA\left(\mathbf{P}-\mathrm{Ag}^{+}-\mathbf{T}_{-\mathrm{H}}\right)$, respectively. All six CD spectra show a small negative Cotton effect at around $300 \mathrm{~nm}$. Cotton effects in this region are normally not due to DNA. As the artificial nucleobase $\mathbf{P}$ slightly absorbs light in the visible region (up to $c a .400 \mathrm{~nm}$ ), ${ }^{16}$ the Cotton effect must stem from the presence of $\mathbf{P}$ within the base pair stack. This in turn means that the nucleobase suggested to extrude from the P:T-containing duplex in the presence of $\mathrm{AgNO}_{3}$ at pH 6.8 and 5.5 is likely to be the thymine residue.

\section{Development of a molecular beacon}

The fact that the metal-free P:C and P:T base pairs display clearly different affinities towards $\mathrm{Ag}^{+}$renders them potentially useful for the detection of single-nucleotide polymorphisms (SNPs). SNPs are common variations among the DNA of individuals of the same species. They are expected to be a genetic reason for a varying drug response of different individuals. ${ }^{21}$ Hence, methods for the detection of SNPs are highly interesting against the background of personalized medicine..$^{22} \mathrm{~A}$ molecular beacon is an oligonucleotide probe that fluoresces in the presence of a perfectly matching complementary sequence. ${ }^{23}$ By using the nucleoside analogue $\mathbf{P}$, a molecular beacon was developed that hybridizes with a target sequence only if the complementary nucleobase is a cytosine (Scheme 1). The sequence used in this study has previously been shown to be ideally suited as a molecular beacon. ${ }^{24}$

As can be seen from the fluorescence spectra shown in Fig. 5, the substantial stability differences of a P:C and $\mathbf{P}: \mathbf{T}$ base pair in the presence of $\mathrm{Ag}^{+}$can be successfully exploited to generate a molecular beacon capable of discriminating cytosine and thymine. The fluorescence at $525 \mathrm{~nm}$ upon excitation at $495 \mathrm{~nm}$ 


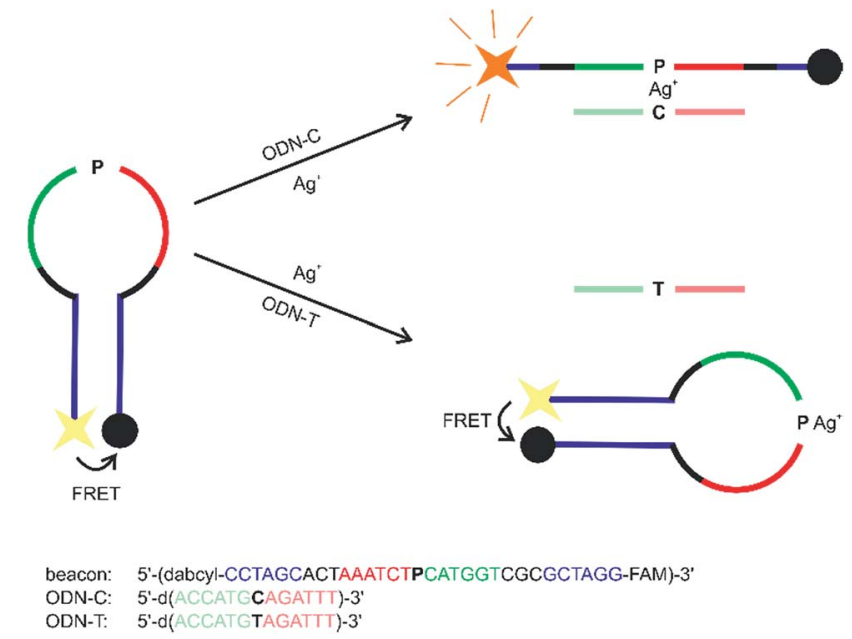

Scheme 1 Design of a molecular beacon to detect cytosine/thymine SNPs based on the formation of a metal-mediated base pair.

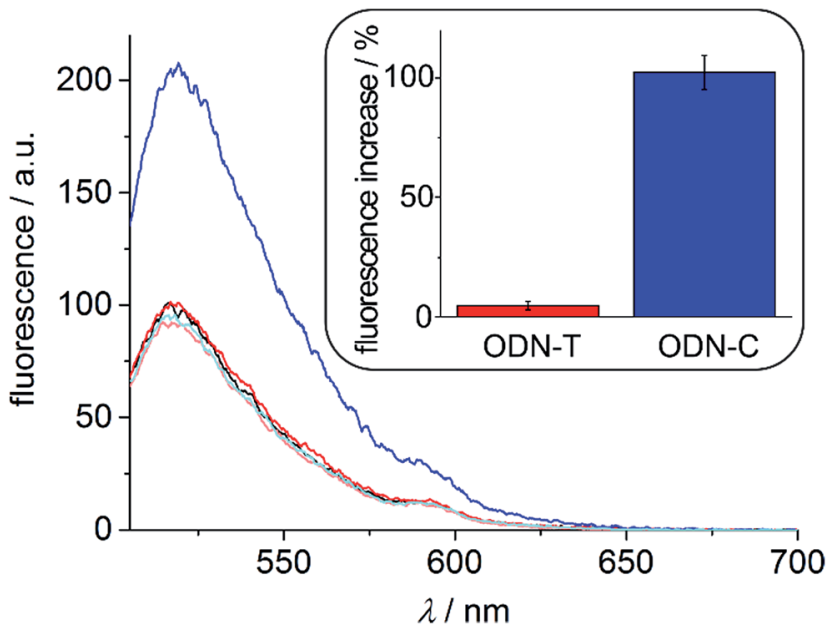

Fig. 5 Fluorescence spectra of the molecular beacon upon excitation at $495 \mathrm{~nm}$. Molecular beacon (-); molecular beacon + ODN-T $+\mathrm{Ag}^{+}$ $(-)$; molecular beacon + ODN-C $+\mathrm{Ag}^{+}(-)$; molecular beacon + ODN-T without $\mathrm{Ag}^{+}(-)$; molecular beacon $+\mathrm{ODN}-\mathrm{C}$ without $\mathrm{Ag}^{+}(-)$. The inset shows the average percent increase of the fluorescence at $525 \mathrm{~nm}$ in the presence of $\mathrm{Ag}^{+}$and the respective oligonucleotide probe (including standard deviation of the mean of three independent measurements). All spectra have been normalized with respect to the spectrum of the molecular beacon.

remains essentially unchanged in the presence of $\mathrm{Ag}^{+}$and the oligonucleotide probe ODN-T with a central thymine residue, whereas it increases by $100 \%$ when $\mathrm{Ag}^{+}$and probe ODN-C with a central cytosine moiety are present. In the absence of $\mathrm{Ag}^{+}$, the beacon is not capable of discriminating ODN-C from ODN-T (Fig. 5), indicating the significance of metal-mediated base pair formation in the sensing process.

\section{Conclusions}

A molecular beacon that discriminates cytosine from thymine via the formation of $\mathrm{a} \mathrm{Ag}^{+}$-mediated base pair has been developed. Towards this end, a nucleoside analogue containing the ligand $1 H$-imidazo[4,5- $f][1,10]$ phenanthroline $\mathbf{P}$ was incorporated into a DNA oligonucleotide. With cytosine in the complementary position, a strongly stabilizing $\mathrm{Ag}^{+}$-mediated base pair is formed. In contrast, the corresponding oligonucleotide sequence containing a thymine instead of the cytosine residue forms a more stable duplex in the absence of $\mathrm{Ag}^{+}$. The molecular beacon makes use of the significantly different acidity constants of cytosine and thymine and the fact that $\mathrm{Ag}^{+}$, which is site-specifically bound by the bidentate ligand $\mathbf{P}$, is not able to replace the thymine $\mathrm{N}-\mathrm{H}$ proton under neutral or acidic conditions. It can be envisaged that such a molecular beacon may be suitable for the detection of single-nucleotide polymorphisms. Clearly, metal-mediated base pairs capable of discriminating the canonical purine nucleobases need to be developed next.

\section{Experimental section}

\section{Determination of the $\mathrm{p} K_{\mathrm{a}}$ values}

The $\mathrm{p} K_{\mathrm{a}}$ values of $\mathbf{1}$ and $\mathbf{P}$ were determined by recording $\mathrm{pD}$ dependent NMR chemical shifts. $\mathrm{pD}$ values of $\mathrm{D}_{2} \mathrm{O}$ solutions were determined by adding 0.4 to the $\mathrm{pH}$ meter reading. ${ }^{25} \mathrm{p} K_{\mathrm{a}}$ values in $\mathrm{H}_{2} \mathrm{O}$ were calculated from the $\mathrm{p} K_{\mathrm{a}}^{*}$ values in $\mathrm{D}_{2} \mathrm{O}$ according to eqn (1). ${ }^{26}$

$$
\mathrm{p} K_{\mathrm{a}}^{*}=1.015 \mathrm{p} K_{\mathrm{a}}+0.45
$$

The experimental pD-dependent chemical shift data were fitted with a non-linear least-squares curve fit. The equations used in these fits were taken from the literature or are given in the ESI. $\dagger^{27}$ The $\mathrm{p} K_{\mathrm{a}}$ values reported in Table 1 represent weighted means of the individual values determined from the changes in the NMR chemical shifts of the individual hydrogen atom.

\section{Computational details}

All calculations have been performed using the Amsterdam Density Functional (ADF) program ${ }^{28}$ using relativistic density functional theory at the ZORA-BLYP-D/TZ2P for geometry optimization and energies. ${ }^{29}$ Solvation in water is simulated using the conductor-like screening model (COSMO). ${ }^{30}$ The stationary points of the monomer and the base pairs were verified to be minima on the potential energy surface (PES) through vibrational analysis. The complexes have also been computed planar to simulate the situation in the DNA helix. See ESI $\dagger$ for more information.

\section{Synthetic procedures}

$(S)$-3-(1H-Imidazo[4,5-f][1,10]phenanthrolin-1-yl)propane-1,2$\operatorname{diol}(\mathbf{P})$ and the artificial phosphoramidite required for the DNA synthesis were prepared as reported previously. ${ }^{\mathbf{1 6 , 1 7}}$ The synthesis of $\mathbf{1}$ is reported in the ESI. $\dagger$ 6-Carboxyfluorescein (6-FAM CPG), 5'-dabcyl phosphoramidite and the phosphoramidites of the natural nucleosides were purchased from Glen Research. Oligonucleotides were prepared in the DMT-off mode 
on a K\&A Laborgeräte H8 DNA/RNA synthesizer following standard protocols (except for a threefold coupling time for the artificial phosphoramidite) and purified as reported previously. ${ }^{17}$ Cleavage of the molecular beacon from solid support and deprotection were achieved by treatment with $500 \mu \mathrm{L}$ of aqueous ammonia for $30 \mathrm{~min}$ at room temperature and subsequent treatment with $500 \mu \mathrm{L}$ of methyl amine. The desalted oligonucleotides were characterized by MALDI-ToF mass spectrometry: $5^{\prime}$-d(GAGGGAPAGAAAG): calcd for $[\mathrm{M}+\mathrm{H}]^{+}$: $4148 \mathrm{Da}$, found: $4148 \mathrm{Da}$; $5^{\prime}$-d(CTTTCTTTCCCTC): calcd for [M + $\mathrm{H}]^{+}$: $3803 \mathrm{Da}$, found: $3804 \mathrm{Da} ; 5^{\prime}-\mathrm{d}($ CTTTCTCTCCCTC): calcd for $[\mathrm{M}+\mathrm{H}]^{+}: 3788 \mathrm{Da}$, found: $3788 \mathrm{Da}$; beacon: calcd for $[\mathrm{M}+\mathrm{Na}]^{+}$: $10546 \mathrm{Da}$, found: $10548 \mathrm{Da}$; ODN-T: calcd for $[\mathrm{M}+\mathrm{H}]^{+}: 3947$ Da, found: $3947 \mathrm{Da}$; ODN-C: calcd for $[\mathrm{M}+\mathrm{H}]^{+}$: $3933 \mathrm{Da}$, found: 3933 Da. MALDI-ToF mass spectra were recorded on a Bruker Reflex IV instrument using a 3-hydroxypicolinic acid/ammonium citrate matrix. For quantification of the oligonucleotides, a molar extinction coefficient of $\varepsilon_{260}=10.0 \mathrm{~cm}^{2} \mathrm{mmol}^{-1}$ was used for $\mathbf{P}$.

\section{Spectroscopy}

UV and CD spectra were recorded of solution containing $1 \mu \mathrm{M}$ oligonucleotide duplex, $150 \mathrm{mM} \mathrm{NaClO}$, and $5 \mathrm{mM}$ buffer of MOPS ( $\mathrm{pH}$ 6.8), MES ( $\mathrm{pH}$ 5.5), or borate ( $\mathrm{pH}$ 9.0). UV spectra were recorded on a CARY BIO 100 spectrophotometer. Temperature-dependent denaturation curves were recorded between $10{ }^{\circ} \mathrm{C}$ and $70{ }^{\circ} \mathrm{C}$ with a heating/cooling rate of $1{ }^{\circ} \mathrm{C}$ $\min ^{-1}$ and a data interval of $1^{\circ} \mathrm{C}$. UV absorbance was normalized according to $A_{\text {norm }}=\left(A-A_{\min }\right) /\left(A_{\max }-A_{\min }\right)$ at $260 \mathrm{~nm}$. Melting temperatures were derived from the maxima of the derivatives of the annealing curves. CD spectra were recorded at $10{ }^{\circ} \mathrm{C}$ on a Jasco J-815 spectrometer. The spectra were smoothed, and a manual baseline correction was applied. Fluorescence spectra were recorded on a Jasco FP-6500 instrument with excitation at $495 \mathrm{~nm}$ and an emission range of 505$700 \mathrm{~nm}$ at a PMT voltage of $520 \mathrm{~V}$. The fluorescence intensity of the molecular beacon was measured in solutions containing $0.05 \mu \mathrm{M}$ beacon, $50 \mathrm{mM} \mathrm{NaClO}_{4}, 2.5 \mathrm{mM} \mathrm{Mg}\left(\mathrm{ClO}_{4}\right)_{2}, 5 \mathrm{mM}$ MES buffer ( $\mathrm{pH}$ 5.5) at room temperature before and after right after adding ODN-C or ODN-T along with 10 equiv. of $\mathrm{AgNO}_{3}$.

\section{Acknowledgements}

Support by COST Action CM1105, the DFG (SFB 858), and the NWO is gratefully acknowledged. Biswarup Jash is a recipient of an NRW Graduate School of Chemistry fellowship. We thank Prof. Bart Jan Ravoo for access to the fluorescence spectrometer and Dipl.-Ing. Jutta Kösters for solving the crystal structure.

\section{References}

1 T. J. Bandy, A. Brewer, J. R. Burns, G. Marth, T. Nguyen and E. Stulz, Chem. Soc. Rev., 2011, 40, 138.

2 E. Stulz and G. H. Clever, DNA in Supramolecular Chemistry and Nanotechnology, John Wiley \& Sons, Chichester, 2015.
3 (a) J. Müller, Eur. J. Inorg. Chem., 2008, 3749; (b) Y. Takezawa and M. Shionoya, Acc. Chem. Res., 2012, 45, 2066; (c) G. H Clever, C. Kaul and T. Carell, Angew. Chem., Int. Ed., 2007, 46, 6226; (d) Y. Tanaka, J. Kondo, V. Sychrovský, J. Šebera, T. Dairaku, H. Saneyoshi, H. Urata, H. Torigoe and A. Ono, Chem. Commun., 2015, 51, 17343.

4 (a) S. Kumbhar, S. Johannsen, R. K. O. Sigel, M. P. Waller and J. Müller, J. Inorg. Biochem., 2013, 127, 203; (b) S. Johannsen, N. Megger, D. Böhme, R. K. O. Sigel and J. Müller, Nat. Chem., 2010, 2, 229; (c) J. Kondo, Y. Tada, T. Dairaku, H. Saneyoshi, I. Okamoto, Y. Tanaka and A. Ono, Angew. Chem., Int. Ed., 2015, 54, 13323; (d) H. Yamaguchi, J. Šebera, J. Kondo, S. Oda, T. Komuro, T. Kawamura, T. Dairaku, Y. Kondo, I. Okamoto, A. Ono, J. V. Burda, C. Kojima, V. Sychrovský and Y. Tanaka, Nucleic Acids Res., 2014, 42, 4094; (e) J. Kondo, T. Yamada, C. Hirose, I. Okamoto, Y. Tanaka and A. Ono, Angew. Chem., Int. Ed., 2014, 53, 2385; (f) C. Kaul, M. Müller, M. Wagner, S. Schneider and T. Carell, Nat. Chem., 2011, 3, 794.

5 S. Atwell, E. Meggers, G. Spraggon and P. G. Schultz, J. Am. Chem. Soc., 2001, 123, 12364.

6 A. Ono, H. Torigoe, Y. Tanaka and I. Okamoto, Chem. Soc. Rev., 2011, 40, 5855.

7 (a) X. Tan, S. Litau, X. Zhang and J. Müller, Langmuir, 2015, 31, 11305; (b) K. Tanaka, A. Tengeiji, T. Kato, N. Toyama and M. Shionoya, Science, 2003, 299, 1212; (c) G. H. Clever, K. Polborn and T. Carell, Angew. Chem., Int. Ed., 2005, 44, 7204; (d) M. Su, M. Tomás-Gamasa and T. Carell, Chem. Sci., 2015, 6, 632.

8 (a) E.-K. Kim and C. Switzer, Org. Lett., 2014, 16, 4059; (b) B. D. Heuberger, D. Shin and C. Switzer, Org. Lett., 2008, 10, 1091; (c) C. Switzer, S. Sinha, P. H. Kim and B. D. Heuberger, Angew. Chem., Int. Ed., 2005, 44, 1529; (d) I. Sinha, C. Fonseca Guerra and J. Müller, Angew. Chem., Int. Ed., 2015, 54, 3603; (e) D. A. Megger, C. Fonseca Guerra, J. Hoffmann, B. Brutschy, F. M. Bickelhaupt and J. Müller, Chem.-Eur. J., 2011, 17, 6533; $(f)$ H. Mei, I. Röhl and F. Seela, J. Org. Chem., 2013, 78, 9457; (g) S. K. Jana, X. Guo, H. Mei and F. Seela, Chem. Commun., 2015, 51, 17301; (h) H. Yang, H. Mei and F. Seela, Chem.-Eur. J., 2015, 21, 10207; ( $i$ ) D. Ukale, V. S. Shinde and T. Lönnberg, Chem.-Eur. J., 2016, 22, 7917; (j) Y. Takezawa, S. Yoneda, J.-L. H. A. Duprey, T. Nakama and M. Shionoya, Chem. Sci., 2016, 7, 3006; (k) N. Santamaría-Díaz, J. M. MéndezArriaga, J. M. Salas and M. A Galindo, Angew. Chem., Int. Ed., 2016, 55, 6170.

9 P. Scharf and J. Müller, ChemPlusChem, 2013, 78, 20.

10 A. Ono and H. Togashi, Angew. Chem., Int. Ed., 2004, 43, 4300.

11 (a) S. Liu, G. H. Clever, Y. Takezawa, M. Kaneko, K. Tanaka, X. Guo and M. Shionoya, Angew. Chem., Int. Ed., 2011, 50, 8886; (b) T. Ehrenschwender, W. Schmucker, C. Wellner, T. Augenstein, P. Carl, J. Harmer, F. Breher and H.-A. Wagenknecht, Chem.-Eur. J., 2013, 19, 12547.

12 J. C. Léon, L. Stegemann, M. Peterlechner, S. Litau, G. Wilde, C. A. Strassert and J. Müller, Bioinorg. Chem. Appl., 2016, 7485125. 
13 (a) H. Urata, E. Yamaguchi, T. Funai, Y. Matsumura and S.-i. Wada, Angew. Chem., Int. Ed., 2010, 49, 6516; (b) T. Kobayashi, Y. Takezawa, A. Sakamoto and M. Shionoya, Chem. Commun., 2016, 52, 3762.

14 K. S. Park, C. Jung and H. G. Park, Angew. Chem., Int. Ed., 2010, 49, 9757.

15 (a) S. Taherpour, O. Golubev and T. Lönnberg, Inorg. Chim. Acta, 2016, 452, 43; (b) S. Taherpour, O. Golubev and T. Lönnberg, J. Org. Chem., 2014, 79, 8990; (c) S. Taherpour, H. Lönnberg and T. Lönnberg, Org. Biomol. Chem., 2013, 11, 991.

16 B. Jash, J. Neugebauer and J. Müller, Inorg. Chim. Acta, 2016, 452, 181.

17 P. Scharf, B. Jash, J. A. Kuriappan, M. P. Waller and J. Müller, Chem.-Eur. J., 2016, 22, 295.

18 B. Lippert, Prog. Inorg. Chem., 2005, 54, 385.

19 W. A. E. McBryde, Can. J. Chem., 1965, 43, 3472.

20 H. Walba and R. W. Isensee, J. Org. Chem., 1961, 26, 2789.

21 J. J. McCarthy and R. Hilfiker, Nat. Biotechnol., 2000, 18, 505.
22 J. Wang, G. S. Y. Pang, S. S. Chong and C. G. L. Lee, Curr. Drug Metab., 2012, 13, 978.

23 S. Tyagi and F. R. Kramer, Nat. Biotechnol., 1996, 14, 303.

24 R. Yang, J. Jin, L. Long, Y. Wang, H. Wang and W. Tan, Chem. Commun., 2009, 322.

25 R. Lumry, E. L. Smith and R. R. Glantz, J. Am. Chem. Soc., 1951, 73, 4330.

26 R. B. Martin, Science, 1963, 139, 1198.

27 R. Tribolet and H. Sigel, Eur. J. Biochem., 1987, 163, 353.

28 (a) G. te Velde, F. M. Bickelhaupt, E. J. Baerends, C. Fonseca Guerra, S. J. A. van Gisbergen, J. G. Snijders and T. Ziegler, J. Comput. Chem., 2001, 22, 931; (b) ADF2013, SCM, Theoretical Chemistry, Vrije Universiteit, Amsterdam, The Netherlands, http://www.scm.com.

29 (a) S. Grimme, J. Comput. Chem., 2006, 27, 1787; (b) E. van Lenthe, E. J. Baerends and J. G. Snijders, J. Chem. Phys., 1994, 101, 9783.

30 (a) A. Klamt, J. Phys. Chem., 1995, 99, 2224; (b) C. C. Pye and T. Ziegler, Theor. Chem. Acc., 1999, 101, 396. 